\section{Reply to D. Vordermark and T. Pelz and R. Mazzola et al}

Vordermark and Pelz ${ }^{1}$ and Mazzola et $\mathrm{al}^{2}$ question the application of a radiation dose-response relationship acquired from a historical cohort to patients currently being treated. We fully agree that our study has some limitations. However, assuming a latency of radiation effects of perhaps 10 years, those effects cannot be assessed directly until at least 10 years after the exposure, by which time radiotherapy methods will have changed. As shown in one of our studies, ${ }^{3}$ the increased incidence of cardiovascular diseases after Hodgkin lymphoma (HL) becomes apparent only at 10 years after radiotherapy and is highest after around 20 years. Three-dimensional computed tomography (CT) planning has been widely used only since the year 2000. Therefore, the full consequences of treatment with CT-planned radiotherapy cannot yet be evaluated directly.

Vordermark and Pelz ${ }^{1}$ indicate that treatment with lowerenergy cobalt-60 or orthovoltage therapy may lead to overdosing in the anterior portions of the heart.

We agree that errors in the estimated biologically effective dose to individual cardiac structures in the anterior heart may be more substantial than those for mean heart dose (MHD). However, even with individual CT scans, accurate assessment of the dose received by individual structures, such as the coronary arteries, remains challenging. ${ }^{4}$ The exact critical cardiac structure for radiation-induced ischemic heart disease remains uncertain, and the majority of the good-quality evidence is currently based on estimates of MHD rather than dose to individual cardiac structures. ${ }^{5}$ Furthermore, our method of estimating MHD may result in slightly different errors in the estimates for cobalt-60 and megavolt treatments because of differences in the beam characteristics. However, our previous assessment of the dosimetry method used ${ }^{6}$ showed that the intraclass correlation coefficient (ICC) between simulation film-based and CT-based MHD estimation for patients treated with cobalt-60 is high (ICC, $0.88 ; 95 \%$ CI, 0.71 to 1.06 ) and comparable to the ICC of patients treated with megavolt treatment (ICC, 0.85 ; 95\% CI, 0.77 to 0.94). It is true that slightly more variation was found for the patients treated with cobalt-60 (average difference, 1.8 Gy; 95\% limits of agreement, -0.5 to 4.2 ) than for the patients treated with megavolt equipment (average difference, $0.02 \mathrm{~Gy}$; 95\% limits of agreement, -5.5 to 5.6), but no significant departure from agreement between the techniques was found. In addition, in our study, fewer than $5 \%$ of patients treated with mediastinal radiotherapy received cobalt- 60 or orthovoltage treatment. Thus, the impact of these techniques on MHDs estimated for the cohort is likely to be negligible.

We agree with Mazzola et $\mathrm{al}^{2}$ that combined modality therapy should still be considered the standard approach in early-stage HL, preferably by using involved-node or involved-site radiotherapy. ${ }^{7,8}$

Currently, the only reason to not use radiotherapy in treating early-stage HL is reasonable concern over the risk of late effects.
Although our approach has acknowledged limitations, the derivation of a dose-response for coronary heart disease after radiotherapy for HL allows quantification, at least in relative terms, of the reduction in risk that can be achieved with modern radiotherapy techniques. For example, the MHD for patients who received radiotherapy with a mantle technique has been reported as 27.5 Gy compared with 7.7 Gy with involved-node radiotherapy. ${ }^{9}$ This average 19.8 Gy reduction in MHD would, on the basis of our study, lead to an expected $146 \%$ relative reduction in the risk of ischemic heart disease. This is reassuring for modern radiation oncologists and can be useful in counseling patients who are receiving treatment. However, these predictions will need to be confirmed by future studies that observe patients treated in the modern era over several decades. Technologies such as deep inspiration breath-hold, ${ }^{10}$ and perhaps even proton beam therapy, ${ }^{11}$ promise to limit heart dose and therefore cardiac risk at some point in the future.

In summary, we agree that our method has some unavoidable limitations in terms of the historical assessment of radiation exposure and that comparison of the exposure used in our study to that received from modern techniques is challenging. For now, this type of dose-response relationship is the best we have for estimating radiation-related coronary heart disease risk in patients with HL past and present. In our view, to paraphrase Mazzola et al, ${ }^{2}$ it is better to learn what we can from a classic black and white movie than to wait until we have figured out the plot in the latest digital blockbuster.

\section{Frederika A. van Nimwegen}

The Netherlands Cancer Institute, Amsterdam, Netherlands

\section{David J. Cutter}

University of Oxford, Oxford, United Kingdom

\section{Michael Schaapveld}

The Netherlands Cancer Institute, Amsterdam, Netherlands

\section{Sarah C. Darby}

University of Oxford, Oxford, United Kingdom

\section{Berthe M.P. Aleman and Flora E. van Leeuwen}

The Netherlands Cancer Institute, Amsterdam, Netherlands

\section{AUTHORS' DISCLOSURES OF POTENTIAL CONFLICTS OF INTEREST}

Disclosures provided by the authors are available with this article at www.jco.org.

\section{REFERENCES}

1. Vordermark D, Pelz T: Coronary heart disease after mediastinal radiotherapy for Hodgkin lymphoma: Can risk calculations from historic cohorts be used today? J Clin Oncol 34:2939-2940, 2016

2. Mazzola R, Levra NG, Alongi F: Radiation dose-response relationship for risk of coronary heart disease in survivors of Hodgkin lymphoma. J Clin Oncol 34:29402941, 2016

3. van Nimwegen FA, Schaapveld M, Janus CP, et al: Cardiovascular disease after Hodgkin lymphoma treatment: 40-year disease risk. JAMA Intern Med 175: 1007-1017, 2015 
4. Lorenzen EL, Taylor CW, Maraldo $\mathrm{M}$, et al: Inter-observer variation in delineation of the heart and left anterior descending coronary artery in radiotherapy for breast cancer: A multi-centre study from Denmark and the UK. Radiother Oncol 108:254-258, 2013

5. Darby SC, Ewertz M, McGale P, et al: Risk of ischemic heart disease in women after radiotherapy for breast cancer. N Engl J Med 368:987-998, 2013

6. van Nimwegen FA, Cutter DJ, Schaapveld M, et al: Simple method to estimate mean heart dose from Hodgkin lymphoma radiation therapy according to simulation X-rays. Int J Radiat Oncol Biol Phys 92:153-160, 2015

7. Raemaekers JM, André MP, Federico M, et al: Omitting radiotherapy in early positron emission tomography-negative stage $1 /$ II Hodgkin lymphoma is associated with an increased risk of early relapse: Clinical results of the preplanned interim analysis of the randomized EORTC/LYSA/FIL H10 trial. J Clin Oncol 32: 1188-1194, 2014
8. Specht $L$, Yahalom J, Illidge $T$, et al: Modern radiation therapy for Hodgkin lymphoma: Field and dose guidelines from the International Lymphoma Radiation Oncology Group (ILROG). Int J Radiat Oncol Biol Phys 89:854-862, 2014

9. Maraldo MV, Brodin NP, Vogelius IR, et al: Risk of developing cardiovascular disease after involved node radiotherapy versus mantle field for Hodgkin lymphoma. Int J Radiat Oncol Biol Phys 83:1232-1237, 2012

10. Aznar MC, Maraldo MV, Schut DA, et al: Minimizing late effects for patients with mediastinal Hodgkin lymphoma: Deep inspiration breath-hold, IMRT, or both? Int J Radiat Oncol Biol Phys 92:169-174, 2015

11. Hoppe BS, Flampouri $S$, Zaiden $R$, et al: Involved-node proton therapy in combined modality therapy for Hodgkin lymphoma: Results of a phase 2 study. Int J Radiat Oncol Biol Phys 89:1053-1059, 2014

DOI: 10.1200/JCO.2016.67.4358; published online ahead of print at www.jco.org on May 2, 2016.

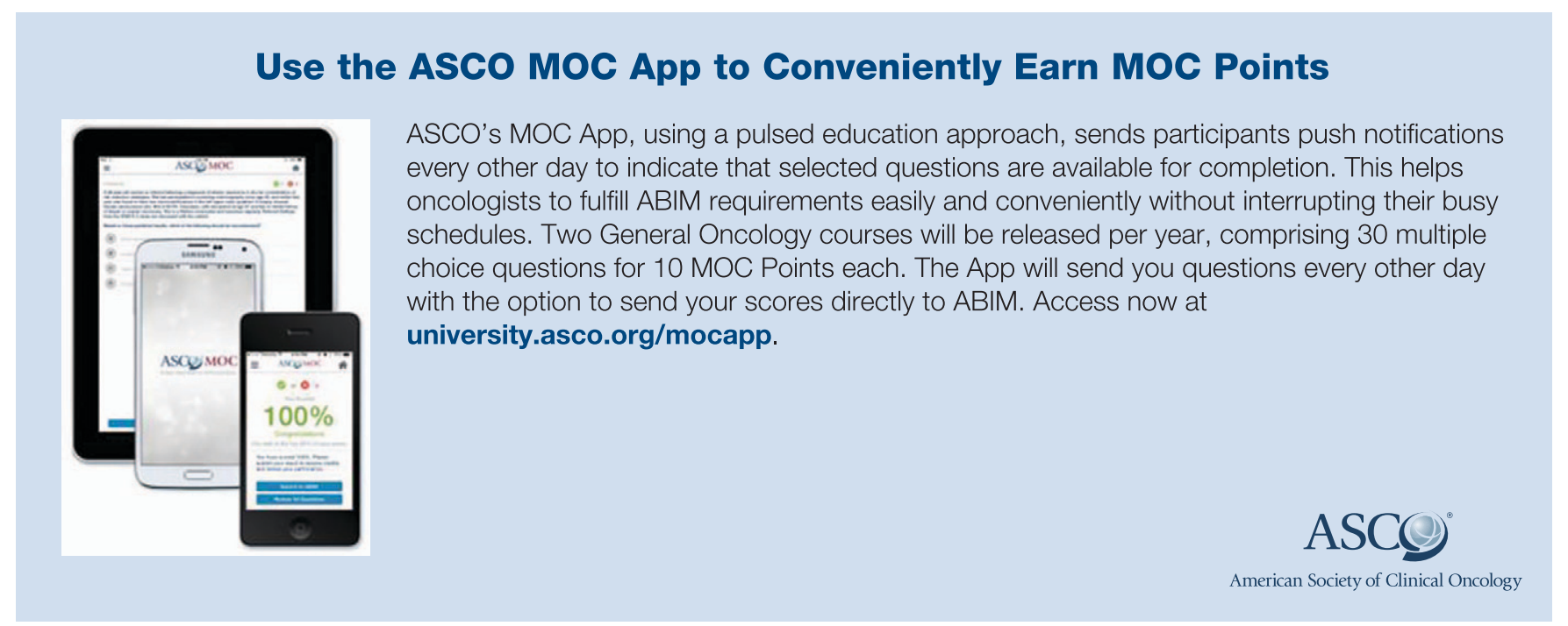




\section{AUTHORS' DISCLOSURES OF POTENTIAL CONFLICTS OF INTEREST}

Reply to D. Vordermark and T. Pelz and R. Mazzola et al

The following represents disclosure information provided by authors of this manuscript. All relationships are considered compensated. Relationships are self-held unless noted. I = Immediate Family Member, Inst = My Institution. Relationships may not relate to the subject matter of this manuscript. For more information about ASCO's conflict of interest policy, please refer to www.asco.org/rwc or jco.ascopubs.org/site/ifc.

Frederika A. van Nimwegen

No relationship to disclose

David J. Cutter

No relationship to disclose

Michael Schaapveld

No relationship to disclose

\section{Sarah C. Darby}

No relationship to disclose

Berthe M.P. Aleman

No relationship to disclose

Flora E. van Leeuwen

No relationship to disclose 